\title{
Analysis of Wind Driven Doubly Fed Induction Generator under Transient Conditions
}

\author{
Milkias Berhanu Tuka, Salem Molla Endale \\ mil_beer2000@astu.edu.et, salem.mola@gmail.com \\ Department of Electrical Power and Control Engineering, Adama Science and Technology University \\ Adama, Ethiopia
}

\begin{abstract}
The Doubly-fed induction generator is one of the most effective and frequently used wind power generation systems in the wind power industry. It offers several enticing benefits, including consistent output voltage, low cost, independent control of active and reactive power, and improved power quality. Despite any of the aforementioned advantages of DFIGs, it is precisely impacted by grid interruption. Any sudden appearance of a fault, such as symmetrical or asymmetrical faults, can cause a reduction in stator voltage, oscillations in stator and rotor currents, DC-link overvoltage, and electromagnetic torque pulsations. Such a phenomenon can considerably affect the performance of the DFIG under a transient state if an appropriate protection system is not considered. Thus, in this thesis work, the crowbar protection system is employed for the enhancement of the FRT capability of the wind turbine. The performance of the machine with the existing capacitor bank and crowbar protection is analyzed and compared. Moreover, the MATLAB/Simulink 2015a software is used for modeling and simulation and all system parameters are obtained from ADAMA-II Wind Farm.
\end{abstract}

Keywords-Battery Energy Storage System, Crowbar, Doubly-Fed Induction Generator, Fault Ride Through Capability, MATLAB-Simulink

\section{INTRODUCTION}

\section{A. Background}

Conventional energy sources such as petroleum, coal, gas, and oil are environmentally hazardous. Excessive use of these energy sources tends to increase emissions of carbon dioxide and other harmful gases to the atmosphere. To address this issue, several countries have undertaken research for scientific advances to use renewable and clean energy sources such as wind, solar, geothermal, biomass, and tidal energy. In this regard, among the various renewable energy resources, wind energy is one of the most efficient, clean, and promising ones with the potential to fulfill the world energy demand [1]. Variable speed wind turbine with partial scale power converter also known as doubly fed induction generator is essentially a wound rotor induction generator in which the rotor circuit can be controlled by external devices for variable speed operation. The generator stator is connected to the grid via the transformer, while the rotor connected to the grid is connected using the power converters, the harmonic filters, and the transformer. DFIG has two back-to-back connected pulse width modulation (PWM) converters with a DC-link capacitor mounted between them. Owing to these power converters, power can be supplied or absorbed to/from the grid. The DC-link capacitor is located between the two converters, as energy storage, to keep the voltage fluctuation (or ripple) in the DC-link voltage small [2].

The power converter is comprised of rotor side converters (RSC) and grid side converters (GSC). The primary function of a rotor side converter is to adjust the speed and torque of the machine and regulate active and reactive power independently. The grid-side converter, on the other hand, retains the DC-link voltage constant regardless of the size or direction of the rotor [2]. Figure 1 depicts the DFIG block diagram.

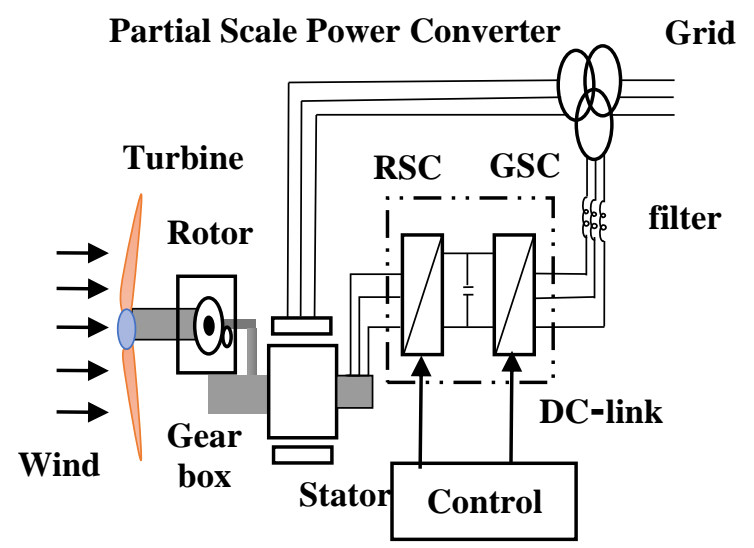

Fig.1. General supply configuration of DFIG [3]

The primary benefits of employing DFIGs in association with wind turbines are [3]:

- The power losses in the converters are lower, leading to the improved overall efficiency

- The mechanical load stresses on wind turbines, which are produced during wind gusts, are reduced.

- Independent control of active and reactive power

- The cost of a DFIG power converter is low, as the power rating of the power converter is typically rated $25 \%$ to $30 \%$ around the rated power

- Improves power quality, reduces torque pulsations, and eliminates electrical power variations, i.e., fewer flickers.

Although DFIG has the aforementioned advantages, it is vulnerable to grid deterioration. Such that, since the stator winding of the machine is directly attached to the grid, when a failure 
occurs, the rotor circuit and converters are subjected to a high overcurrent caused by high transient stator current. In the occurrence of such a fault, the wind turbine must be isolated from the network to secure the converter. However, in most countries, power grid connection codes mandate wind turbines to remain connected to the grid to ensure reliability throughout and after a short-term outage [4]. Grid transmission and distribution operators and wind turbine manufacturers have developed rules (grid code) for the generators to stay connected to the grid during instability. The ability of wind turbines to remain connected to the grid during voltage dips is referred to as Fault ridethrough (FRT) or low voltage ride-through (LVRT) capability. In this thesis work, three significant issues are accurately addressed in an attempt to fulfil the LVRT capability of a wind turbine in a fault state. The first is overcurrent, which can occur in rotor and stator circuits, and the second is overvoltage in a DC-link and the third is electromagnetic fluctuation. The first and second can be attributed to surplus energy causing harm to the power converters [5]. Thus, the main objective of this work is to improve FRT capability under fault conditions by employing a protection system.

\section{B. Significant of the paper work}

The significance of this thesis work is to enhances the LVRT capability of WT by utilizing a crowbar protection scheme in order to restrict the high currents that arise due to voltage dip at the grid terminal. The data essential for modelling the whole system is obtained from ADAMA-II WT Moreover, a detailed comparative analysis between the existing capacitor bank and the crowbar protection scheme under symmetrical fault condition is presented.

\section{DYNAMIC MODELLING OF DOUBLY FED INDUCTION GENERATOR}

The DFIG comprises a stator winding and a rotor winding equipped with a slip ring. The stator is directly connected to the grid. Whereas, the rotor is fed to the grid via a variable frequency converter, which only demands to accommodate a fraction (25-30\%) of the overall power to achieve maximum generator control. It is crucial to recognize the models for the DFIG wind power systems, particularly the dynamic model, for the design of the regulation of the wind power systems. This model represents the operating relationship of the variables in the DFIG power system [6].

The dynamic and transient behavior of the DFIG is analyzed for modeling purposes, and even more precisely for the implementation of the subsequent machine control [6,7].

\section{A. $\quad \alpha, \beta$ Model}

The mathematical model of the three-phase machines is transformed into two-phase stationery, rotor, and synchronous reference frame [8].

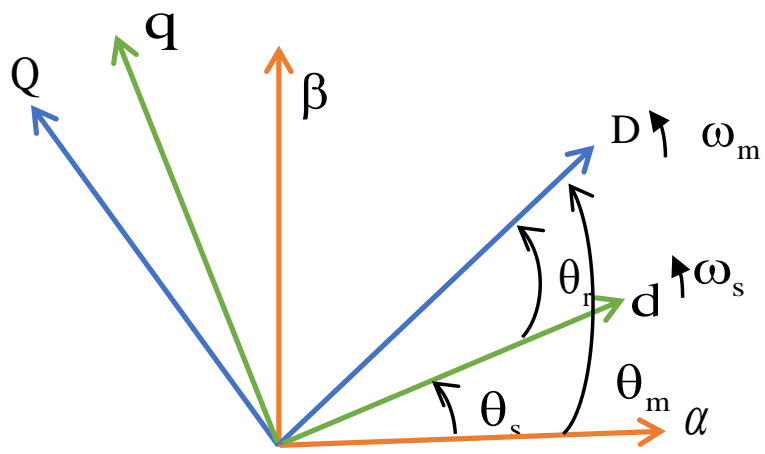

Fig.2. Different reference frames tu ıсpresent spaci vectors of the DFIM [8]

Space vector theory is used to represent the three coils of the stator and rotor independently by two stationary coils $(\alpha, \beta)$ for the stator and two rotating coils DQ for the rotor [8].

Stator and rotor voltage in $(\alpha, \beta)$

$$
\begin{aligned}
& \mathrm{v}_{\alpha \mathrm{s}}=\mathrm{R}_{\mathrm{s}} \mathrm{i}_{\alpha \mathrm{s}}+\frac{\mathrm{d} \psi_{\alpha \mathrm{s}}}{\mathrm{dt}} \\
& \mathrm{v}_{\beta \mathrm{s}}=\mathrm{R}_{\mathrm{s}} \mathrm{i}_{\beta \mathrm{s}}+\frac{\mathrm{d} \psi_{\beta \mathrm{s}}}{\mathrm{dt}} \\
& \mathrm{v}_{\alpha \mathrm{r}}=\mathrm{R}_{\mathrm{r}} \mathrm{i}_{\alpha \mathrm{r}}+\frac{\mathrm{d} \psi_{\alpha \mathrm{r}}}{\mathrm{dt}}+\omega_{\mathrm{m}} \psi_{\beta \mathrm{r}} \\
& \mathrm{v}_{\beta \mathrm{r}}=\mathrm{R}_{\mathrm{r}} \mathrm{i}_{\beta \mathrm{r}}+\frac{\mathrm{d} \psi_{\beta \mathrm{r}}}{\mathrm{dt}}-\omega_{\mathrm{m}} \psi_{\alpha \mathrm{r}}
\end{aligned}
$$

The expressions of the stator and rotor flux in the form of space vector in the stationary reference frame are:

Stator and rotor flux in $(\alpha, \beta)$

$$
\begin{aligned}
& \psi_{\alpha \mathrm{s}}=\mathrm{L}_{\mathrm{s}} \mathrm{i}_{\alpha \mathrm{s}}+\mathrm{L}_{\mathrm{m}} \mathrm{i}_{\alpha \mathrm{s}} \\
& \psi_{\beta \mathrm{s}}=\mathrm{L}_{\mathrm{s}} \mathrm{i}_{\beta \mathrm{s}}+\mathrm{L}_{\mathrm{m}} \mathrm{i}_{\beta \mathrm{s}} \\
& \psi_{\alpha \mathrm{r}}=\mathrm{L}_{\mathrm{m}} \mathrm{i}_{\alpha \mathrm{r}}+\mathrm{L}_{\mathrm{r}} \mathrm{i}_{\alpha \mathrm{r}} \\
& \psi_{\beta \mathrm{r}}=\mathrm{L}_{\mathrm{m}} \mathrm{i}_{\beta \mathrm{r}}+\mathrm{L}_{\mathrm{r}} \mathrm{i}_{\beta \mathrm{r}}
\end{aligned}
$$

Where, $\mathrm{V}_{\alpha \mathrm{s}}, \mathrm{V}_{\alpha \mathrm{r}}, \mathrm{V}_{\beta \mathrm{s}}, \mathrm{V}_{\beta \mathrm{r}}, \mathrm{i}_{\alpha \mathrm{s}}, \mathrm{i}_{\alpha \mathrm{r}}, \mathrm{i}_{\beta \mathrm{s}}, \mathrm{i}_{\beta \mathrm{r}}$ and $\psi_{\alpha \mathrm{s}}, \psi_{\alpha \mathrm{r}}, \psi_{\beta \mathrm{s}}, \psi_{\beta \mathrm{r}}$ are voltages, currents and flux linkages of the stator and rotor in $\alpha, \beta$ axis $\mathrm{R}_{\mathrm{s}}$ and $\mathrm{R}_{\mathrm{r}}$ are the stator and rotor resistance, $\mathrm{L}_{\mathrm{s}}, \mathrm{L}_{\mathrm{r}}$ and $\mathrm{L}_{\mathrm{m}}$ are the stator, rotor, and mutual inductance respectively, $\omega_{\mathrm{m}}$ and $\omega_{\mathrm{s}}$ are the rotor electrical speed. and the stator frequency.

The active and reactive power of the stator and rotor in the $(\alpha, \beta)$ frame is calculated as follows: 
$\mathrm{P}_{\mathrm{s}}=1.5\left(\mathrm{v}_{\alpha \mathrm{s}} \mathrm{i}_{\alpha \mathrm{s}}+\mathrm{v}_{\beta \mathrm{s}} \mathrm{i}_{\beta \mathrm{s}}\right)$

$\mathrm{Q}_{\mathrm{s}}=1.5\left(\mathrm{v}_{\beta \mathrm{s}} \mathrm{i}_{\alpha \mathrm{s}}-\mathrm{v}_{\alpha \mathrm{s}} \mathrm{i}_{\beta \mathrm{s}}\right)$

$\mathrm{P}_{\mathrm{r}}=1.5\left(\mathrm{v}_{\alpha \mathrm{r}} \mathrm{i}_{\alpha \mathrm{r}}+\mathrm{v}_{\beta \mathrm{r}} \mathrm{i}_{\beta \mathrm{r}}\right)$

$\mathrm{Q}_{\mathrm{r}}=1.5\left(\mathrm{v}_{\beta \mathrm{r}} \mathrm{i}_{\alpha \mathrm{r}}-\mathrm{v}_{\alpha \mathrm{r}} \mathrm{i}_{\beta \mathrm{r}}\right)$

Where, $P_{s}, P_{r}, Q_{s}$ and $Q_{r}$ are the active and reactive power of the stator and rotor in the $(\alpha, \beta)$ frame. The electromagnetic torque of the machine can be determined using the following equivalent expressions:

$\mathrm{T}_{\mathrm{em}}=1.5\left(\frac{\mathrm{L}_{\mathrm{m}}}{\sigma \mathrm{L}_{\mathrm{r}} \mathrm{L}_{\mathrm{s}}}\right) \mathrm{p} \operatorname{Im}\left\{\psi_{\mathrm{r}} \cdot \psi_{\mathrm{s}}\right\}$

Where, $\mathrm{p}$ is the pole pair of the machine and $\sigma=1-\mathrm{L}_{\mathrm{m}}^{2} /\left(\mathrm{L}_{\mathrm{s}} \cdot \mathrm{L}_{\mathrm{r}}\right)$ is the leakage coefficient

\section{B. $\quad d-q$ Model}

The transformation of the three-phase induction machine model to a two-phase (d-q) equivalent circuit results in the eradication of time-varying inductances in the voltage equations [9]. The dynamic equation of a three-phase DFIG in a twophase direct-quadrature $(\mathrm{d}-\mathrm{q})$ reference frame is expressed as:

The stator and rotor voltage in the $\mathrm{d}-\mathrm{q}$ reference frame

$$
\begin{aligned}
& \mathrm{v}_{\mathrm{ds}}=\mathrm{R}_{\mathrm{s}} \mathrm{i}_{\mathrm{ds}}+\frac{\mathrm{d} \psi_{\mathrm{ds}}}{\mathrm{dt}}-\omega_{\mathrm{s}} \psi_{\mathrm{qs}} \\
& \mathrm{v}_{\mathrm{qs}}=\mathrm{R}_{\mathrm{s}} \mathrm{i}_{\mathrm{qs}}+\frac{\mathrm{d} \psi_{\mathrm{qs}}}{\mathrm{dt}}+\omega_{\mathrm{s}} \psi_{\mathrm{ds}} \\
& \mathrm{v}_{\mathrm{dr}}=\mathrm{R}_{\mathrm{r}} \mathrm{i}_{\mathrm{dr}}+\frac{\mathrm{d} \psi_{\mathrm{dr}}}{\mathrm{dt}}-\omega_{\mathrm{r}} \psi_{\mathrm{qr}} \\
& \mathrm{v}_{\mathrm{qr}}=\mathrm{R}_{\mathrm{r}} \mathrm{i}_{\mathrm{qr}}+\frac{\mathrm{d} \psi_{\mathrm{qr}}}{\mathrm{dt}}+\omega_{\mathrm{r}} \psi_{\mathrm{dr}}
\end{aligned}
$$

The stator and rotor flux in the d-q reference frame

$$
\begin{aligned}
& \psi_{\mathrm{ds}}=\mathrm{L}_{\mathrm{s}} \mathrm{i}_{\mathrm{ds}}+\mathrm{L}_{\mathrm{m}} \mathrm{i}_{\mathrm{dr}} \\
& \psi_{\mathrm{qs}}=\mathrm{L}_{\mathrm{s}} \mathrm{i}_{\mathrm{qs}}+\mathrm{L}_{\mathrm{m}} \mathrm{i}_{\mathrm{qr}} \\
& \psi_{\mathrm{dr}}=\mathrm{L}_{\mathrm{r}} \mathrm{i}_{\mathrm{dr}}+\mathrm{L}_{\mathrm{m}} \mathrm{i}_{\mathrm{ds}} \\
& \psi_{\mathrm{qr}}=\mathrm{L}_{\mathrm{r}} \mathrm{i}_{\mathrm{qr}}+\mathrm{L}_{\mathrm{m}} \mathrm{i}_{\mathrm{qs}}
\end{aligned}
$$

Where, $\mathrm{V}_{\mathrm{ds}}, \mathrm{V}_{\mathrm{dr}}, \mathrm{V}_{\mathrm{qs}}, \mathrm{V}_{\mathrm{qr}}, \mathrm{i}_{\mathrm{ds}}, \mathrm{i}_{\mathrm{dr}}, \mathrm{i}_{\mathrm{qs}}, \mathrm{i}_{\mathrm{qr}}$ and $\psi_{\mathrm{ds}}, \psi_{\mathrm{dr}}, \psi_{\mathrm{qs}}, \psi_{\mathrm{qr}}$ are voltages, currents, and flux linkages of the stator and rotor in the $\mathrm{d}-\mathrm{q}$ axis.

\section{CROWBAR PROTECTION METHOD}

(5) The DFIG based wind power plants are extremely sensitive to grid disruptions, particularly voltage dips. As faults occur and cause voltage dips, control is briefly lost, enabling the current flowing

(6) through the power converter to rise. During this situation, crowbar protection is activated to protect the system from over-currents caused by loss of control. The crowbar creates a low resistance path, isolating the RSC and ensuring that the entire rotor currents circulate through it as shown in Figure 3 [10]. Once the stator and rotor currents decay and the power converters gain control of the machine, the crowbar is deactivated.

The timing of the deactivating crowbar and the value of the series resistor in commercial DFIG exhibit critical effects on converter safety and system recovery. This indicates that early removal of the crowbar does not fulfill the purpose of converter protection, whereas delayed removal results in higher absorption of reactive power from the grid [11]. Crowbar resistance has a major effect as well, with a high value causing a large peak of electromagnetic torque and a low value causing large currents during a voltage dip. As a result, the acceptable value of crowbar resistance is considered appropriate as a balance between certain objectives based on DFIG efficiency and grid code enforcement. The main concern with this protection method is that prolonged use of the rotor crowbar results in loss of torque control and the DFIG to operate as a squirrel cage induction machine and draw stator side magnetization. This results in a high-slip reactive power demand, which degrades stator voltage.

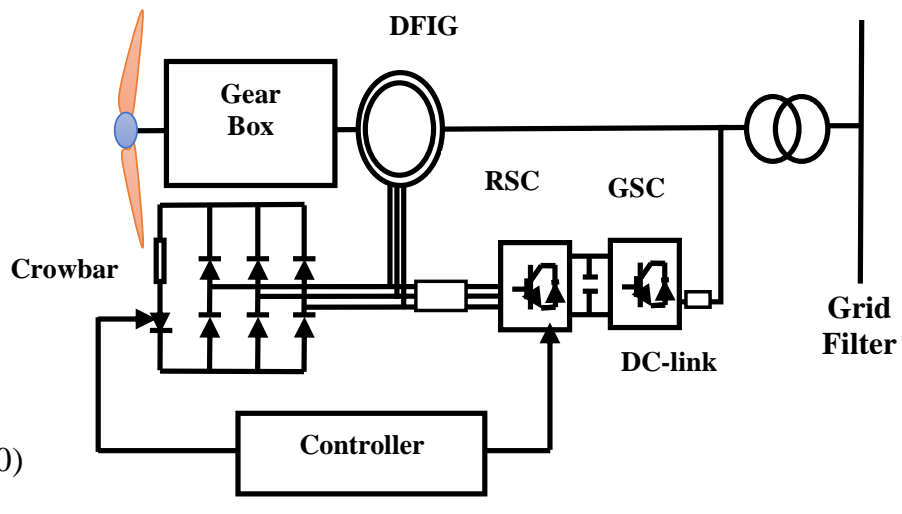

Fig.3. Crowbar protection system

\section{CONTROL SYSTEM FOR DOUBLY FED INDUCTION GENERATOR}

In this paper work, vector control of DFIG in the synchronous reference frame is employed. Among the control strategies, this control technique is widely adopted due to its high accuracy, simple implementation parameters, a good dynamic response under normal and faulty operating 
conditions, and a fixed switching frequency [12$13]$.

\section{A. Rotor Side Control}

The main role of the RSC control is to regulate the active and reactive power separately by controlling the quadrature and the direct axis rotor current [12].

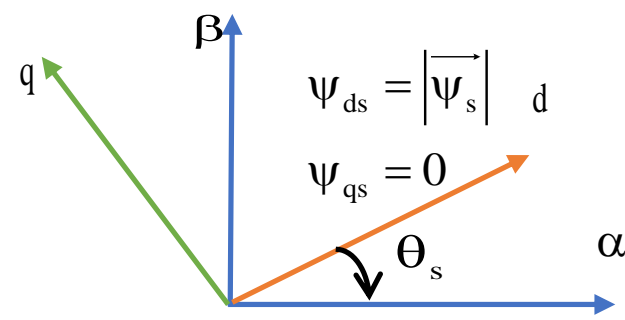

Fig.4. Vector control of the d-q reference aligned with stator flux space vector [13]

Considering stator flux orientation, the relationship between the current and the fluxes can be expressed as follow:

$\psi_{\mathrm{ds}}=\psi_{\mathrm{s}}=\mathrm{i}_{\mathrm{ds}} \mathrm{L}_{\mathrm{s}}+\mathrm{i}_{\mathrm{dr}} \mathrm{L}_{\mathrm{m}}$

$0=\mathrm{i}_{\mathrm{qs}} \mathrm{L}_{\mathrm{s}}+\mathrm{i}_{\mathrm{qr}} \mathrm{L}_{\mathrm{m}}$

From the above equation, the relation between stator and rotor current is obtained

$$
\begin{aligned}
& \mathrm{i}_{\mathrm{ds}}=\frac{1}{\mathrm{~L}_{\mathrm{s}}}\left(\psi_{\mathrm{s}}-\mathrm{L}_{\mathrm{m}} \mathrm{i}_{\mathrm{dr}}\right) \\
& \mathrm{i}_{\mathrm{qs}}=-\frac{\mathrm{L}_{\mathrm{m}}}{\mathrm{L}_{\mathrm{s}}} \mathrm{i}_{\mathrm{qr}}
\end{aligned}
$$

The correlation between the rotor flux and currents is

$$
\begin{aligned}
& \psi_{\mathrm{dr}}=\frac{\mathrm{L}_{\mathrm{m}}}{\mathrm{L}_{\mathrm{s}}} \psi_{\mathrm{ds}}+\sigma \mathrm{L}_{\mathrm{r}} \mathrm{i}_{\mathrm{dr}} \\
& \psi_{\mathrm{qr}}=\sigma \mathrm{L}_{\mathrm{r}} \mathrm{i}_{\mathrm{qr}}
\end{aligned}
$$

Where, $\sigma$ is $\left(1-\frac{\mathrm{L}_{\mathrm{m}}{ }^{2}}{\mathrm{~L}_{\mathrm{s}}}\right)$

In the absence of a small drop in stator resistance, the voltage of the stator and the relationship between the voltage of the rotor and the current can be expressed as follows:

$$
\begin{aligned}
& \mathrm{v}_{\mathrm{ds}}=0 \\
& \mathrm{v}_{\mathrm{qs}}=\mathrm{v}_{\mathrm{g}}=\omega_{\mathrm{s}} \psi_{\mathrm{s}} \\
& \mathrm{v}_{\mathrm{dr}}=\mathrm{R}_{\mathrm{r}} \mathrm{i}_{\mathrm{dr}}-\omega_{\mathrm{r}} \sigma \mathrm{L}_{\mathrm{r}} \mathrm{i}_{\mathrm{qr}}+\sigma \mathrm{L}_{\mathrm{r}} \frac{\mathrm{d}}{\mathrm{dt}} \mathrm{i}_{\mathrm{dr}} \\
& \mathrm{v}_{\mathrm{qr}}=\mathrm{R}_{\mathrm{r}} \mathrm{i}_{\mathrm{qr}}+\omega_{\mathrm{r}} \sigma \mathrm{L}_{\mathrm{r}} \mathrm{i}_{\mathrm{dr}}+\sigma \mathrm{L}_{\mathrm{r}} \frac{\mathrm{d}}{\mathrm{dt}} \mathrm{i}_{\mathrm{qr}}
\end{aligned}
$$

The active and reactive power of the stator as well as the electromagnetic torque, which is governed directly by the quadrature current, can be formulated as

$$
\begin{aligned}
& \mathrm{P}_{\mathrm{s}}=-\frac{3 \mathrm{~L}_{\mathrm{m}}}{2 \mathrm{~L}_{\mathrm{s}}}\left(\mathrm{v}_{\mathrm{qs}} \mathrm{i}_{\mathrm{qr}}\right) \\
& \mathrm{Q}_{\mathrm{s}}=\frac{3 \mathrm{v}_{\mathrm{qs}}}{2 \mathrm{~L}_{\mathrm{s}}}\left(\psi_{\mathrm{ds}}-\mathrm{L}_{\mathrm{m}} \mathrm{i}_{\mathrm{dr}}\right) \\
& \mathrm{T}_{\mathrm{e}}=-\frac{3}{2} \mathrm{p} \frac{\mathrm{L}_{\mathrm{m}}}{\mathrm{L}_{\mathrm{m}}}\left(\psi_{\mathrm{ds}} \mathrm{i}_{\mathrm{qr}}\right)
\end{aligned}
$$

It is necessary to achieve $\theta_{\mathrm{r}}$ for reference frame transformation. So, first, $90^{\circ}$ is subtracted from the estimated angle to get the angle of the stator voltage space vector.

$$
\begin{aligned}
& \theta_{\mathrm{v}}=\tan ^{-1}\left(\frac{\mathrm{v}_{\beta}}{\mathrm{v}_{\alpha}}\right) \\
& \theta_{\mathrm{s}}=\theta_{\mathrm{v}}-90^{\circ} \\
& \theta_{\mathrm{r}}=\theta_{\mathrm{s}}-\left(\mathrm{p} \cdot \theta_{\mathrm{m}}\right)_{\mathrm{elec}}
\end{aligned}
$$

\section{GRID SIDE CONTROL}

The purpose of GSC is to maintain a constant DClink voltage and to provide reactive support to the grid [6]. A vector-control technique with a reference frame oriented along the grid voltage vector position is used. The d-axis current is used to regulate the DC-link voltage and the q-axis current is used to regulate the reactive power in the PWM voltage source converter [13].

By using Clark and park transformation, threephase can be expressed in a two-phase stationary and rotating reference frame

$$
\begin{aligned}
& \mathrm{v}_{\alpha \mathrm{g}}=\mathrm{R}_{\mathrm{g}} \mathrm{i}_{\alpha \mathrm{g}}+\mathrm{L}_{\mathrm{g}} \frac{\mathrm{di} \mathrm{i}_{\alpha \mathrm{g}}}{\mathrm{dt}}+\mathrm{v}_{\alpha \mathrm{g}_{-} \text {conv }} \\
& \mathrm{v}_{\beta \mathrm{g}}=\mathrm{R}_{\mathrm{g}} \mathrm{i}_{\beta \mathrm{g}}+\mathrm{L}_{\mathrm{g}} \frac{\mathrm{di}_{\beta \mathrm{g}}}{\mathrm{dt}}+\mathrm{v}_{\beta \mathrm{g}_{-} \text {conv }} \\
& \mathrm{v}_{\mathrm{dg}}=\mathrm{R}_{\mathrm{g}} \mathrm{i}_{\mathrm{dg}}+\mathrm{L}_{\mathrm{g}} \frac{\mathrm{di} \mathrm{dg}_{\mathrm{dg}}}{\mathrm{dt}}-\omega_{\mathrm{e}} \mathrm{L}_{\mathrm{g}} \mathrm{i}_{\mathrm{qg}}+\mathrm{v}_{\mathrm{dg}_{-} \text {conv }} \\
& \mathrm{v}_{\mathrm{qg}}=\mathrm{R}_{\mathrm{g}} \mathrm{i}_{\mathrm{qg}}+\mathrm{L}_{\mathrm{g}} \frac{\mathrm{di} \mathrm{ig}_{\mathrm{qg}}}{\mathrm{dt}}+\omega_{\mathrm{e}} \mathrm{L}_{\mathrm{g}} \mathrm{i}_{\mathrm{dg}}+\mathrm{v}_{\mathrm{qg} \_ \text {conv }}
\end{aligned}
$$

Where, $\mathrm{V}_{\mathrm{dg}}, \mathrm{V}_{\mathrm{qg}}$ are the grid voltages in $\mathrm{d}$-q axis, $\mathrm{V}_{\mathrm{dg} \_ \text {conv }}, \mathrm{V}_{\mathrm{qg} \text { _conv }}$ are the grid-side converter voltages in $\mathrm{d}$-q axis, $\mathbf{i}_{\mathrm{dg}}, \mathbf{i}_{\mathrm{qg}}$ are the grid-side converter currents in $\mathrm{d}-\mathrm{q}$ axis, $\omega_{\mathrm{e}}$ is the electrical angular velocity of the grid voltage. 
The active and reactive power flow between the grid and the grid side converter is denoted as:

$$
\begin{aligned}
& \mathrm{P}_{\mathrm{g}}=1.5\left(\mathrm{v}_{\mathrm{dg}} \mathrm{i}_{\mathrm{dg}}+\mathrm{v}_{\mathrm{qg}} \mathrm{i}_{\mathrm{qg}}\right) \\
& \mathrm{Q}_{\mathrm{g}}=1.5\left(\mathrm{v}_{\mathrm{qg}} \mathrm{i}_{\mathrm{dg}}-\mathrm{v}_{\mathrm{dg}} \mathrm{i}_{\mathrm{qg}}\right)
\end{aligned}
$$

The angular position of the supply voltage is computed as follows:

$$
\theta_{\mathrm{e}}=\int \omega_{\mathrm{e}} \mathrm{dt}=\tan ^{-1}\left[\frac{\mathrm{v}_{\beta \mathrm{g}}}{\mathrm{v}_{\alpha \mathrm{g}}}\right]
$$

\section{MAXIMUM POWER POINT TRACKING CONTROL}

It is essential to acquire the greatest energy from wind energy utilizing distinctive maximum power point tracking (MPPT) control strategies to accomplish viable, compelling, remarkable, and powerful wind energy sources. Maximum power point tracking is employed for the purpose to extract maximum power by maintaining the rotor rotational speed with the adjustment in wind speed, to maintain the tip speed ratio at its optimal value [14].

\section{RESULTS AND DISCUSSION}

In this Section, simulation analysis is carried out using MATLAB/SIMULINK software to evaluate and examine the performance of DFIG during three phase symmetrical fault conditions. Under a faulty state the performance of the double fed induction generator employing crowbar protection mechanisms is evaluated. In order to identify how the crowbar protection system enhances the fault ride through capability, a comparison is made between the existing capacitor banks and the crowbar protection system.

\section{A. Under Grid Fault Condition with the Existing Capacitor Bank}

When a symmetrical fault occurs at a grid terminal, the voltage at the terminal decreases, so do the stator and rotor fluxes of the generator, causing the generator to demagnetize. Moreover, the voltage dip results in electromagnetic torque fluctuation, high stator and rotor current, and DC-link overvoltage [15].

\section{B. RSC Under Grid Fault Condition with Existing Capacitor Bank}

A dynamic simulation is carried out by imposing a three-phase symmetrical fault at the grid terminal for $150 \mathrm{~ms}$ to analyze the DFIG based WT without any protection system applied. The impact of grid fault on the machine is shown in subsequent figures below. When a symmetrical fault occurs, as shown in Figure 5, the stator voltage of the DFIG drops to $10 \%$ of the nominal voltage at the time of $2 \mathrm{sec}$ and remains there for $150 \mathrm{~ms}$. Once the fault is cleared at $2.15 \mathrm{sec}$, the voltage begins to recover from 2.15 to 3.65 seconds. Figure 6 depicts that the rotor speed varies in response to changes in electromagnetic torque. The torque is considerably decreased to zero causing mechanical tension in the gearbox. Figure 7 ( $a$ and $b$ ) depicts that with the fault occurring at 2 seconds, the stator and rotor currents are increased to a high value. Figure 8 indicate that when a failure occurs, both the rotor currents across the d-axis and the q-axis rise to elevated values within 2-2.15 seconds. Even though the rotor side converter can be utilized to compensate for rotor current variation by increasing the rotor voltage reference, it will eventually lose its controlling ability over the machine due to the DFIG having a power converter with a rotor voltage limit. In other words, the converter supplying the rotor will only provide $30 \%$ of the supply voltage, and as a result, the converter reaches its limit rapidly and, as a result, cannot control the generator during a failure [15].

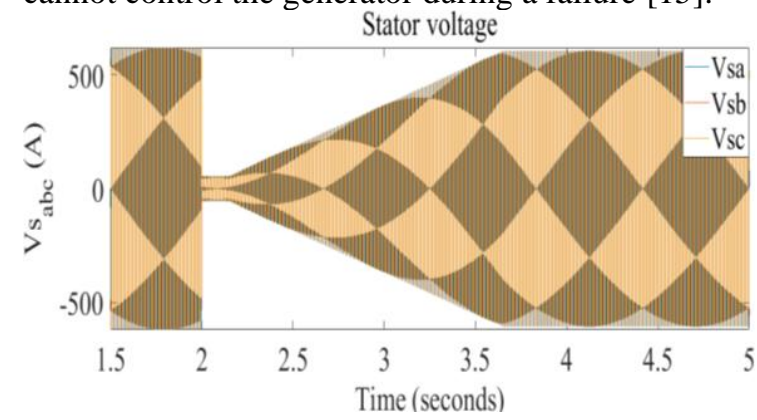

Fig.5. Stator voltage
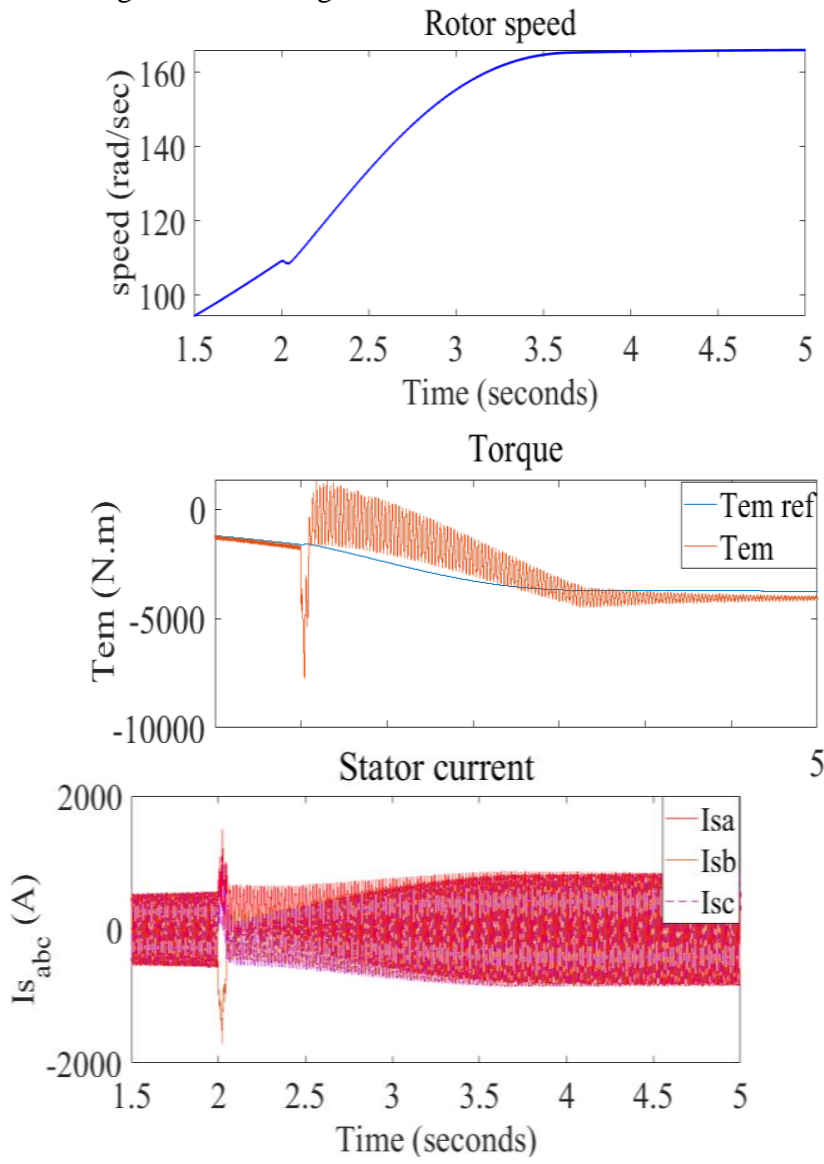


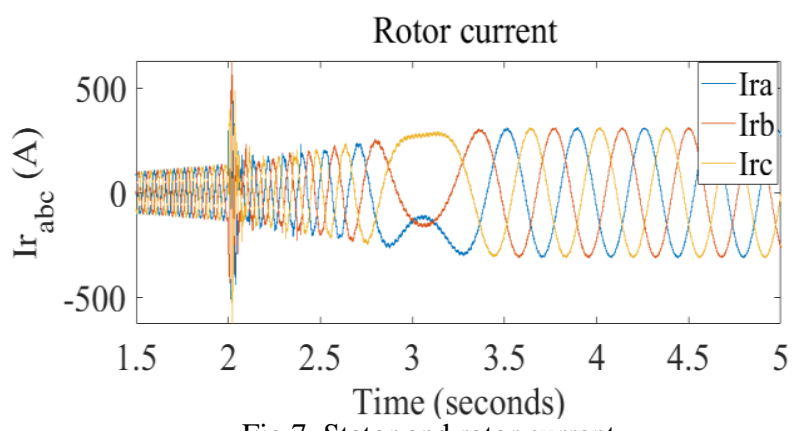

Fig.7. Stator and rotor current
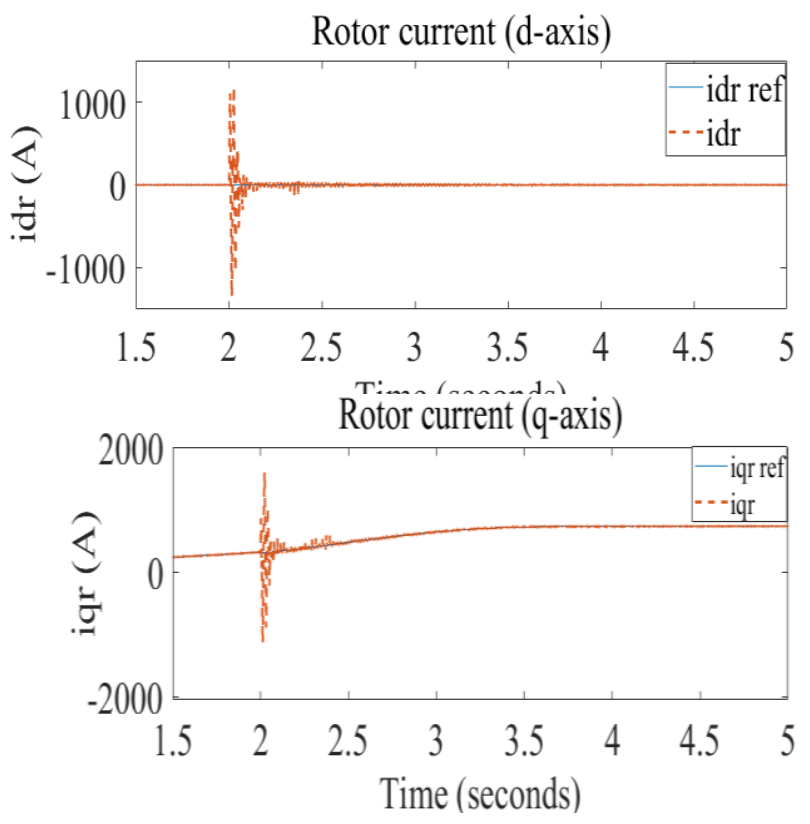

C. GSC Under Grid Fault Condition with Existing Capacitor Bank

When a grid fault occurs, the voltage drops, inhibiting the GSC from transferring the whole power from the rotor to the grid. As a result, the excess energy charges the DC-link capacitor instantly, leading to DC-link overvoltage. Figure 9 elucidates that the stator voltage reduces to $10 \%$ of the nominal voltage at $2 \mathrm{sec}$ and recovers from 2.15 to 3.65 after the clearance of fault. Figure 10 (a) illustrates how the current is observed to be unbalanced as a consequence of the grid faults. Figure 10 (b) portrays variation of the DC-link voltage at a high value of approximately 1350 , which normally results due to overcurrent at the stator and rotor of the system. The grid currents across d-axis and q-axis, as shown in Figure 11, increases to a high value and fluctuates during the occurrence of a fault.

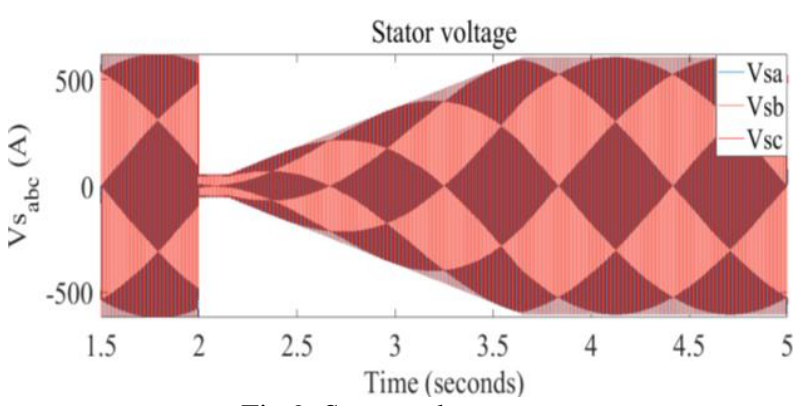

Fig.9. Stator voltage
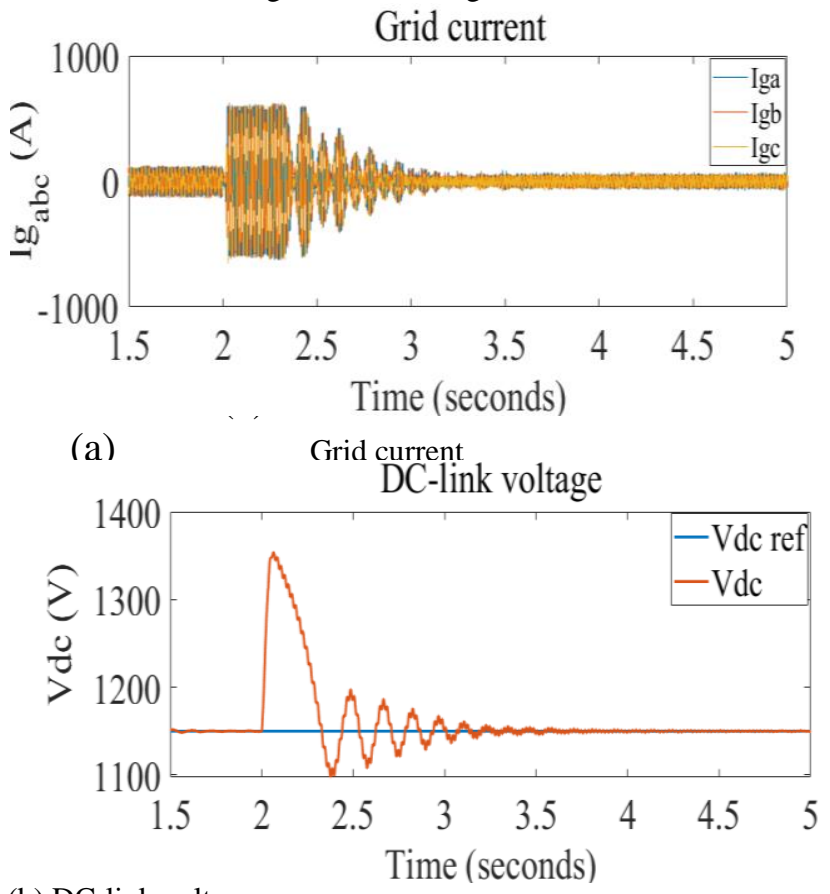

(b) DC-link voltage

Fig.10. Grid current and DC-link voltage

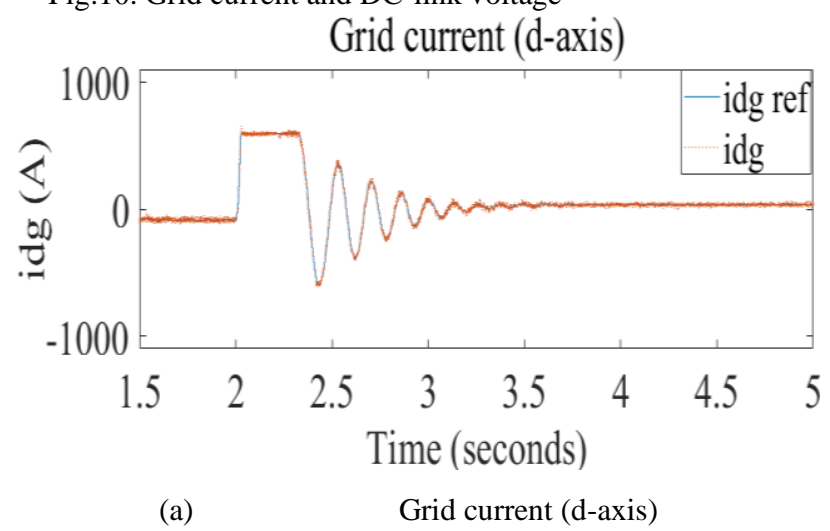

(a)

Grid current (d-axis)

Grid current (q-axis)

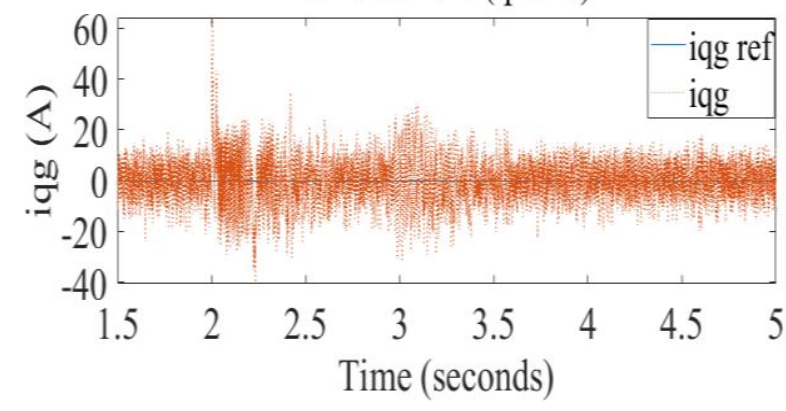

(b) Under Grid Fault Condition with the Crowbar 
As the voltage drops, crowbar protection is triggered, which provides a low resistance path, isolating the RSC and ensuring that all rotor currents pass through it.

i. RSC Under Grid Fault Condition with Crowbar Protection System

Fig.12 (a) demonstrates the voltage dropping to $0.1 \mathrm{pu}$ and remaining at that stage for $150 \mathrm{~ms}$. When the voltage dip is detected, the crowbar protection is activated for 100 milliseconds inhibiting the RSC and protecting it from high currents by allowing the current to pass through the crowbar. Figure 12 (b, d, f) represents how the high rotor and stator current encountered due to the occurrence of fault circulates through the crowbar. The torque and flux are also influenced by the grid fault, as shown in Figure 12 (c, e). The flux is observed to decrease to near zero, and so is the torque. It is realized in Figure 12 (c) that even after the fault has been cleared, the torque does not meet the reference value. This is because torque control is lost when the crowbar is enabled. Once the rotor current reduces and the flux return to its nominal value, and the available converter voltage starts to control the machine, the crowbar is disconnected and RSC is reactivated. The rotor current across the d-axis and q-axis is depicted in Figure $12(\mathrm{~g}, \mathrm{~h})$. As a dip occurs, as required by grid code, increasing the $\mathrm{d}$-axis rotor current will provide progressively reactive power through the stator. However, since the crowbar blocks the RSC during activation, no reactive power can be generated. As a result, it is only after some time $(2.14 \mathrm{sec})$ that reactive power is supplied through the stator.

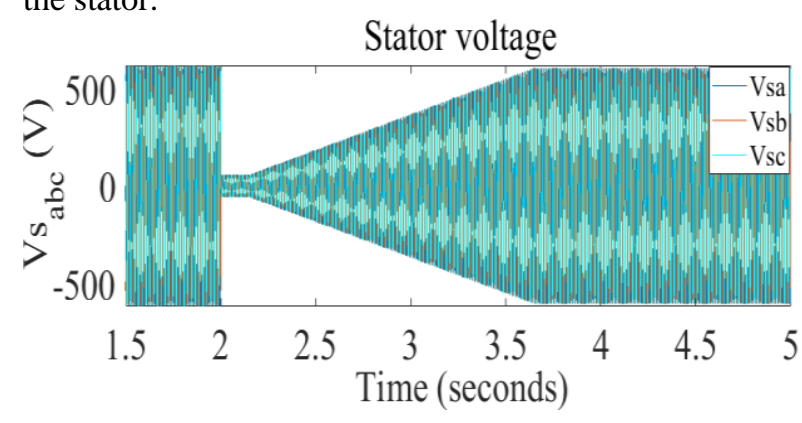

(a) Stator voltage

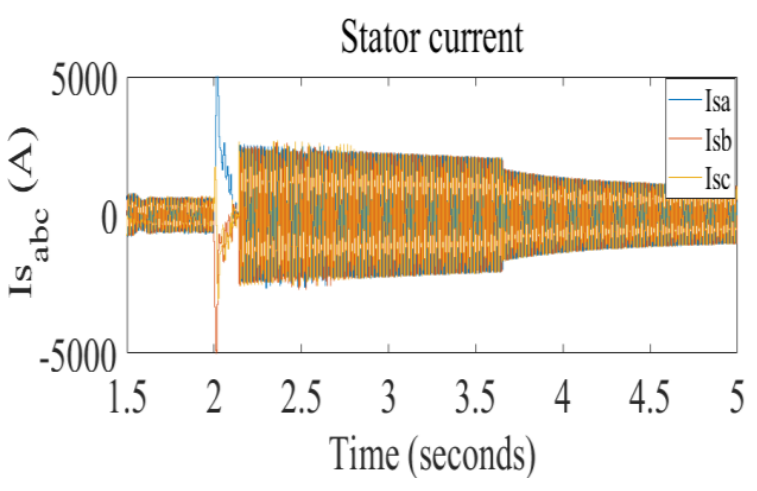

(b) Stator current

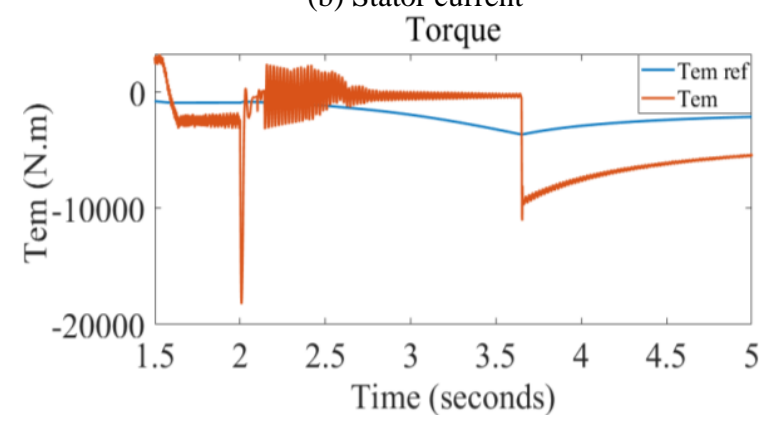

(c) Torque

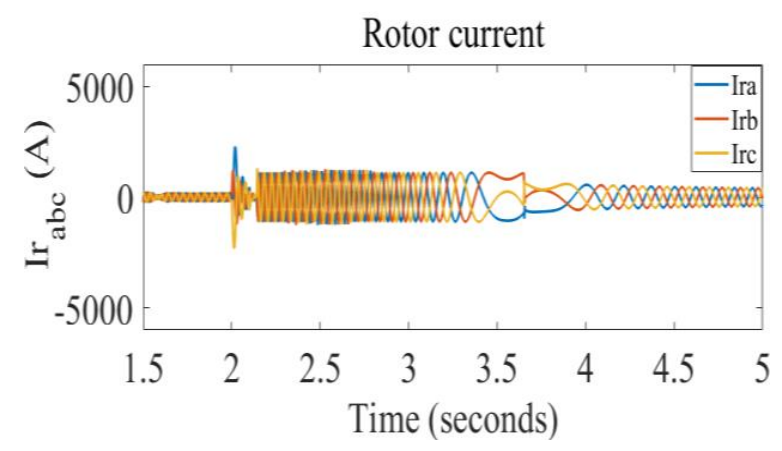

(d) Rotor current

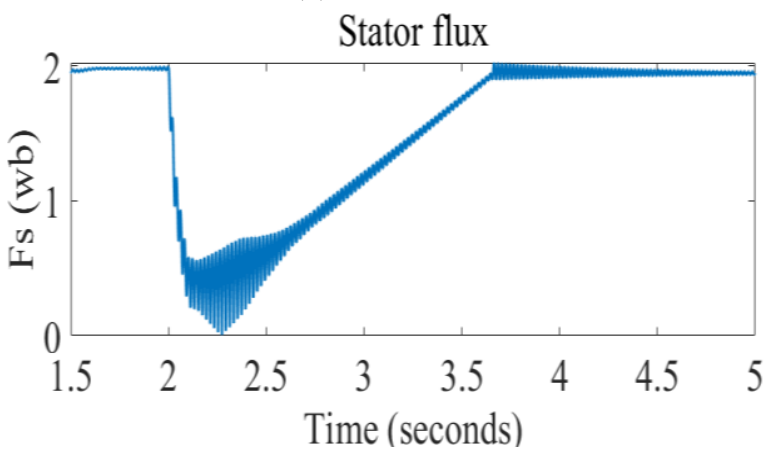

(e) Stator flux 


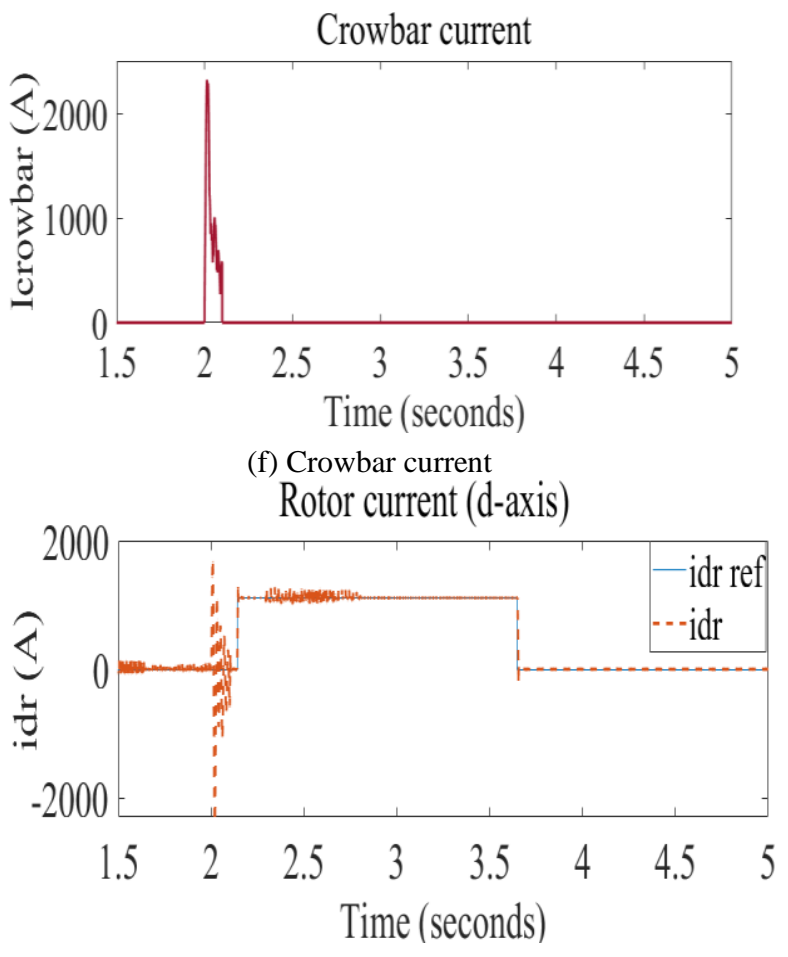

(g) Rotor current (d-axis)

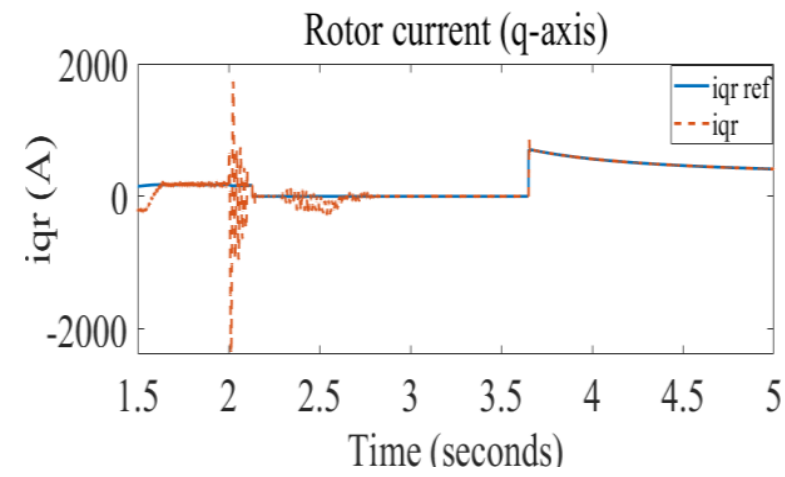

(h) Rotor current (q-axis)

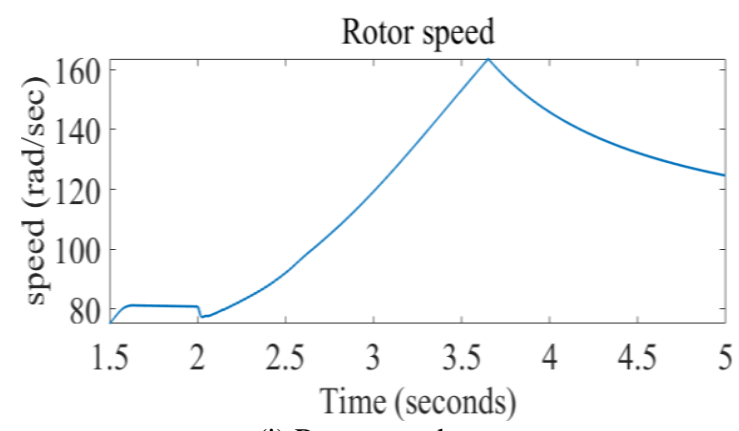

(i) Rotor speed

Fig.12. Performance of DFIG with a crowbar at RSC

ii. GSC Under Grid Fault Condition with Crowbar Protection System

During a fault, the GSC loses its ability to control the DC-link voltage due to the limited value of rotor voltage that the power converter generates. Thus, the performance of DFIG at the GSC is analyzed by applying a protection mechanism at the time control is lost. Fig.13 (a) illustrates how the grid current is maintained constant after the activation of the crowbar. and Fig 13 (b) elucidates that while the crowbar is enabled, no energy is transferred to the DC-link capacitor, and hence the DC-link voltage is more likely to decrease. However, after the crowbar is deactivated and the fault is cleared, the DC-link voltage is observed to return to a steady-state. The grid current across daxis, in Figure 13 (c, d), remains at its nominal value following its reference value after the fault is completely cleared.
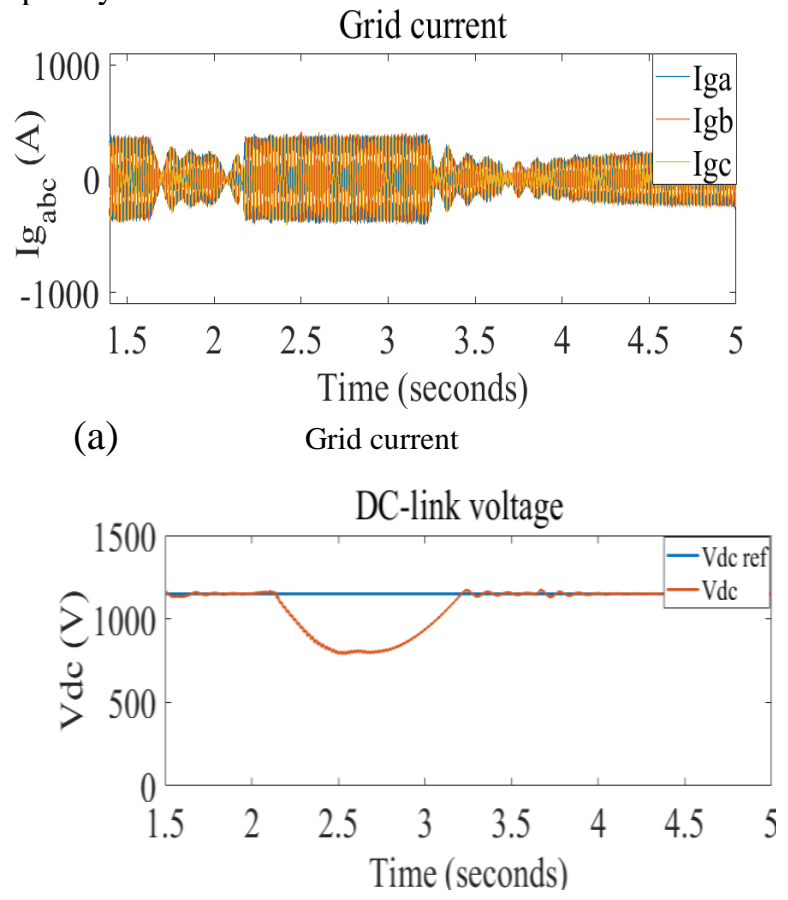

(b) DC-link voltage

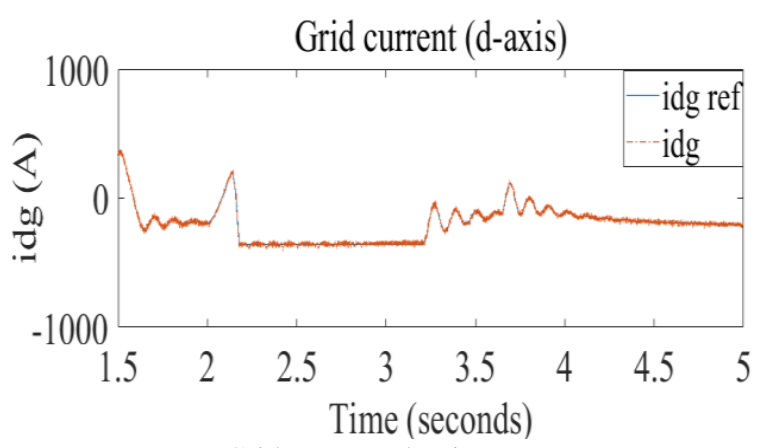

(c) Grid current (d-axis)

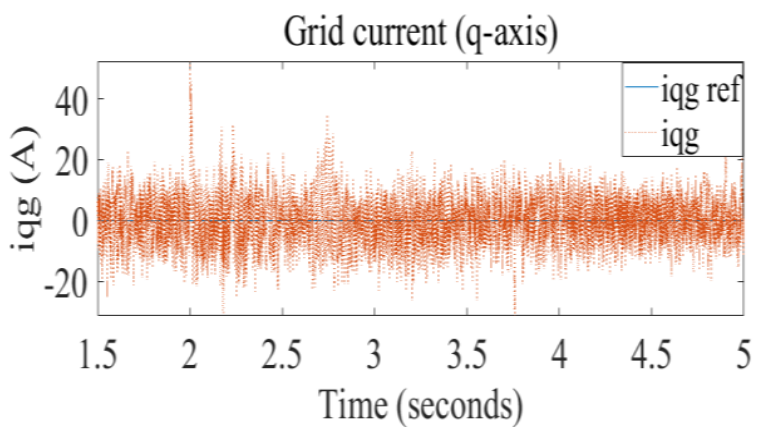

(d) Grid current (q-axis) 
Fig.13. Performance of DFIG with the crowbar at GSC

\section{Comparative Analysis of the Results}

This section provides a thorough comparison of various parameters at the RSC and GSC with the existing capacitor bank and crowbar protection mechanism. Torque, speed, stator and rotor currents, and rotor current across the d-axis are among the parameters used for comparison

i. Comparative Analysis at RSC

Fig. 14 illustrates various parameters at RSC which were used for comparative purposes. A distinct number is assigned to each figure in order to differentiate it. The parameters with the existing capacitor bank are denoted by ' 1 ', the parameters with the crowbar protection system are denoted by ' 2 '. Fig.14 (a1 and a2) demonstrate the torque value with an existing capacitor bank and crowbar protection. Subfigure (a1) depicts that when a fault occurs, a high torque pick is noticed and machine control is lost for 2 to 3.5 seconds. High torque fluctuation is seen, and the actual value of torque is also noted to deviate from its reference value.

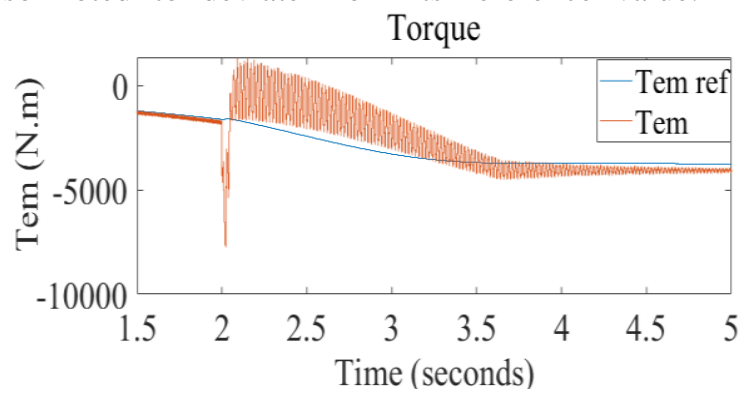

(a1)

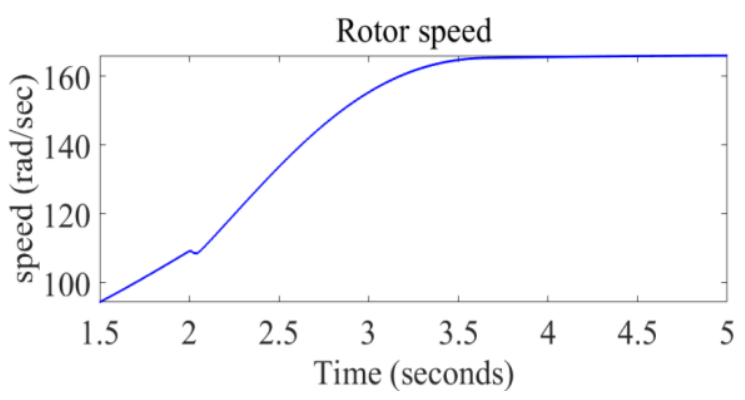

(b1)

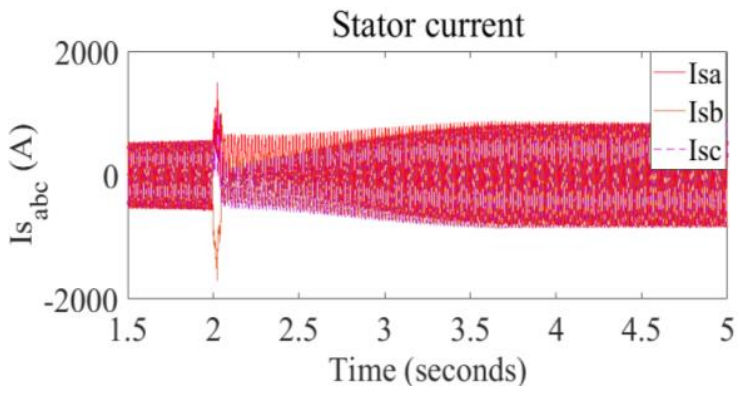

(c1)
Subfigure (a2) displays that with the crowbar activated, even though the fluctuation of torque is minimized, control over torque is lost, and the torque takes time to follow the reference value even after the crowbar is deactivated. Subfigures (c1 and d1) depict stator and rotor currents using the existing capacitor bank. High currents are detected at the occurrence of the fault at $2 \mathrm{sec}$. The power converters will be harmed by these high currents. Subfigures (c2, d2, f2) demonstrate that when the crowbar is activated, high currents flow through it. As a result, the converters are shielded from large currents caused by faults. Subfigure (e1) displays the rotor current across a d-axis using the existing capacitor bank. It is observed that when a defect emerges, the machine does not supply any reactive power, thereby further degrading the voltage at the terminal. In subfigure (e2), it is proven that rising idr supplies reactive power to the grid; however, it is also noted that reactive power is given to the grid only after the crowbar is deactivated (i.e. 2.14sec).

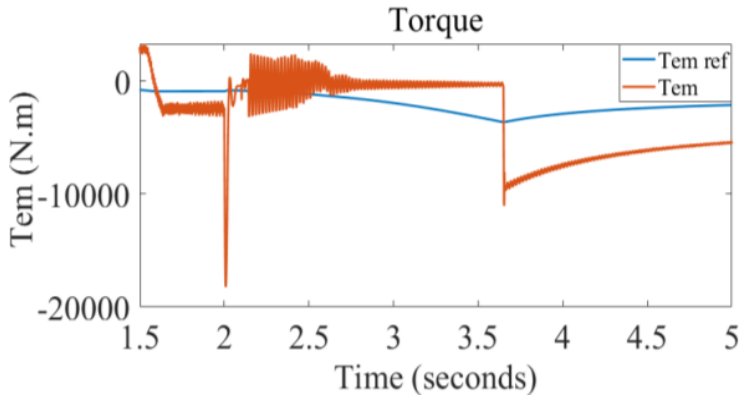

(a2)

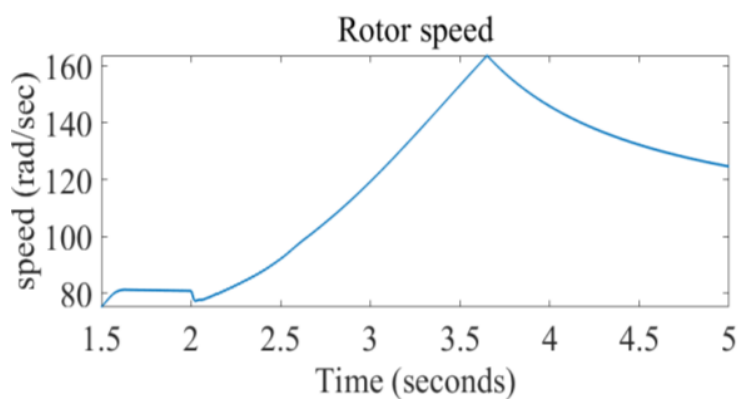

(b2)

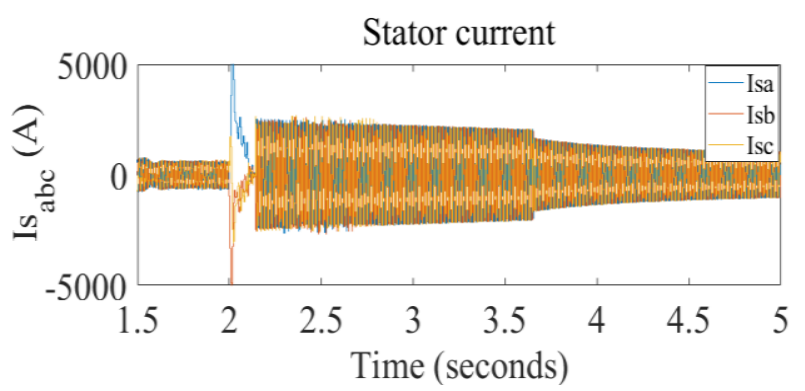

(c2) 


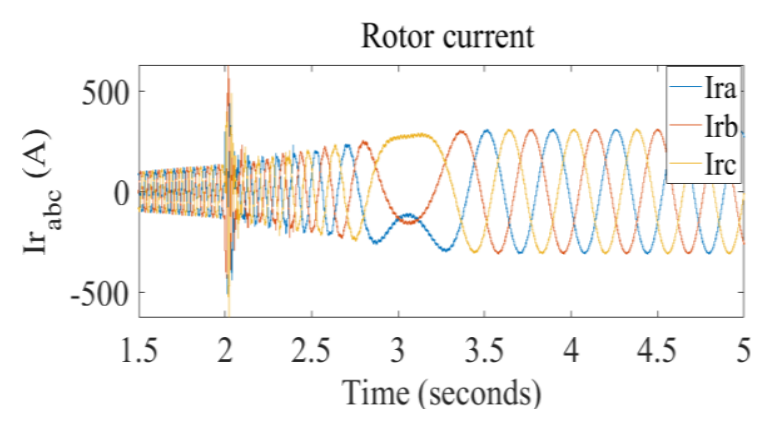

(d1)

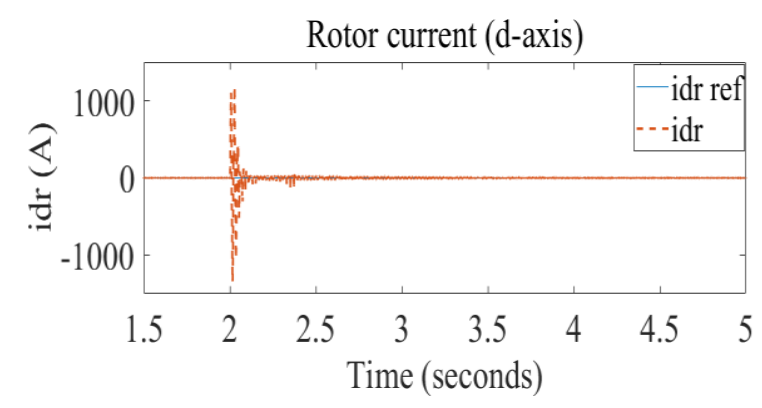

(e1)

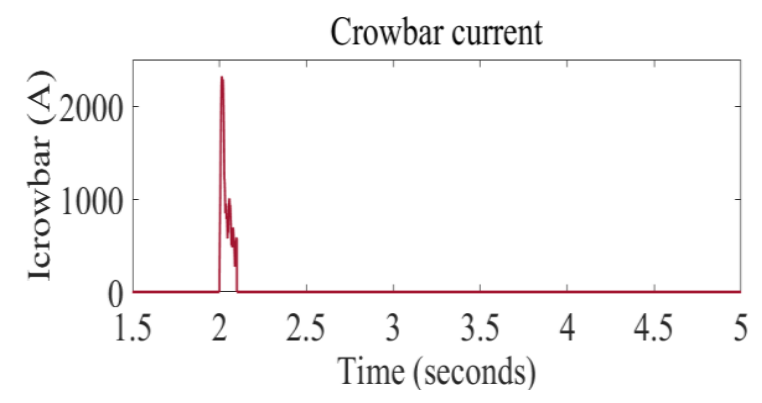

(f1)

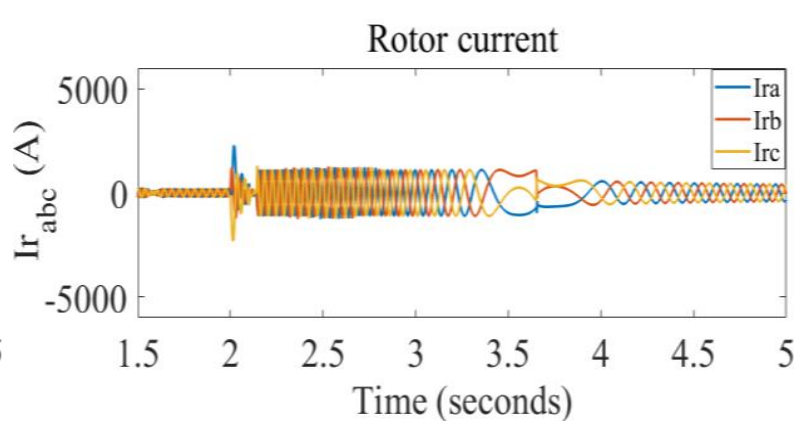

(d2)

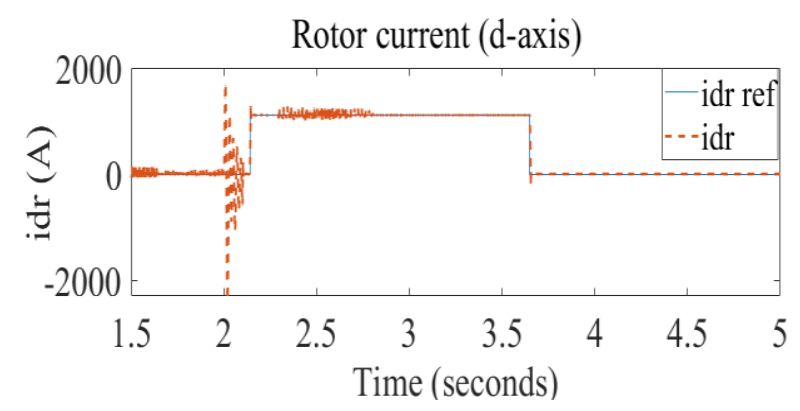

(e2)

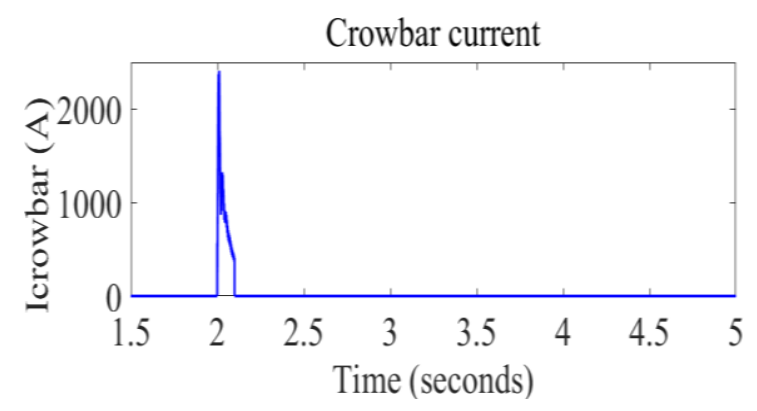

(f2)

\section{ii. Comparative Analysis at GSC}

Fig. 15 depicts a comparison of various parameters at GSC with the existing capacitor bank and crowbar protection system. Subfigure (a1 and a2) demonstrates the current at the grid side converter. It is observed that due to the occurrence of fault this current fluctuates in both methods. However, after the fault is cleared the system is observed to return to its normal operating condition. In subfigure (b1), the DC-link voltage is observed to rise to $1350 \mathrm{v}$. This amount of DC-link voltage will damage the power converter if no protection scheme is applied. When the crowbar is utilized to analysis at RSC

the system, the dc-link voltage drops to a low level as depicted in subfigure (b2). This is due to the fact that the crowbar prevents all energy from passing through the DC-link capacitor causing the dc-link voltage to drop. Subfigures (c1 and c2). exhibit the grid currents across the d-axis. The DC-link voltage is controlled by the d-axis grid current. The grid current across the $\mathrm{d}$-axis is observed to increase, as shown in subfigure (c1). As illustrated in subfigure (c2), the d-axis grid current is observed to reduce when the crowbar protection system is applied to the system. 


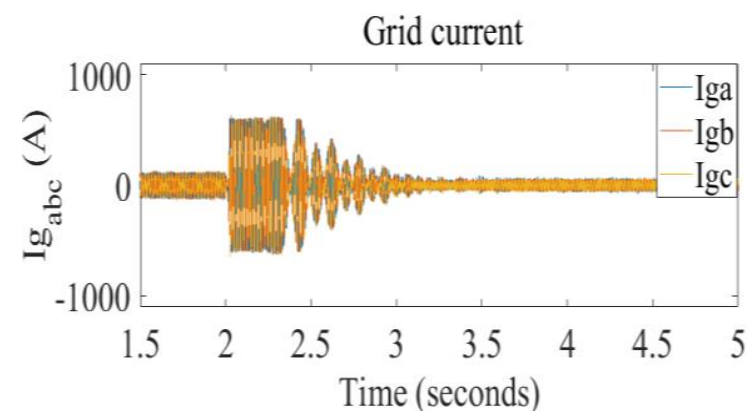

(a1)

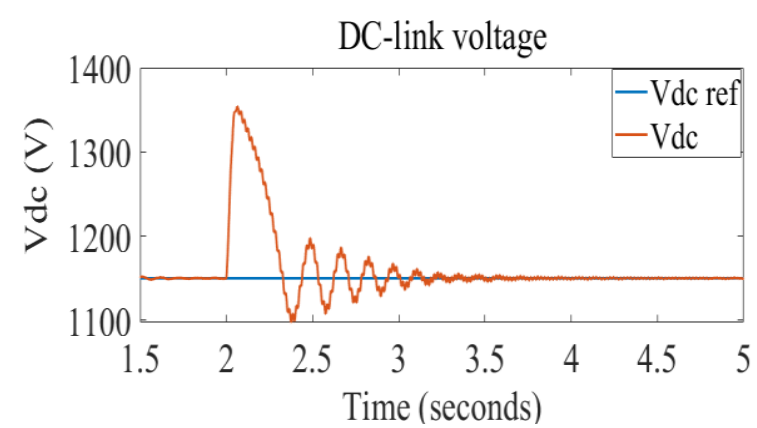

(b1)

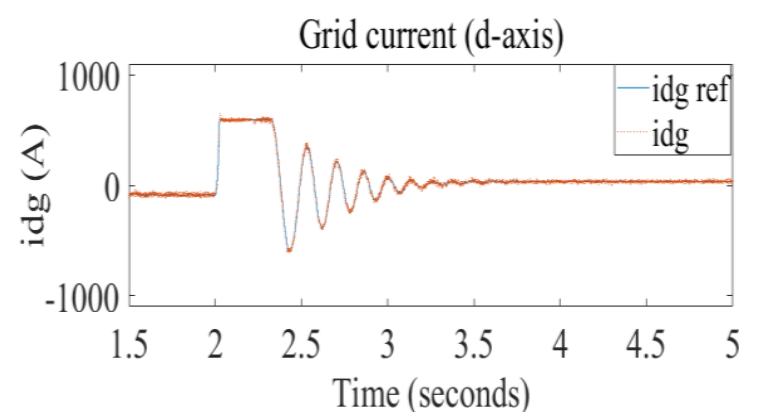

(c1)

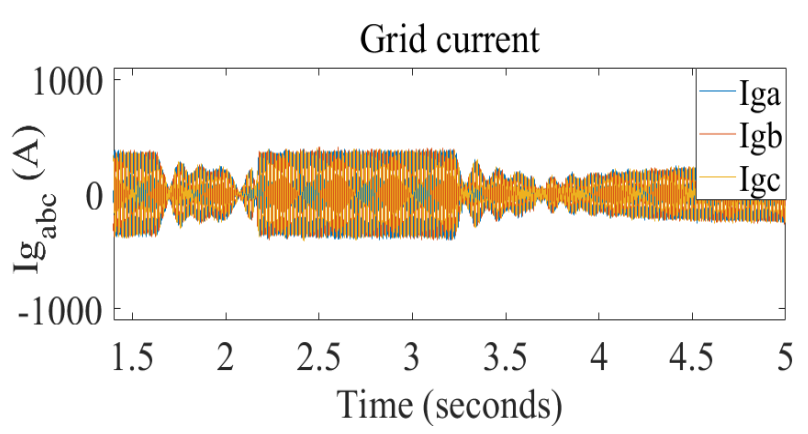

(a2)

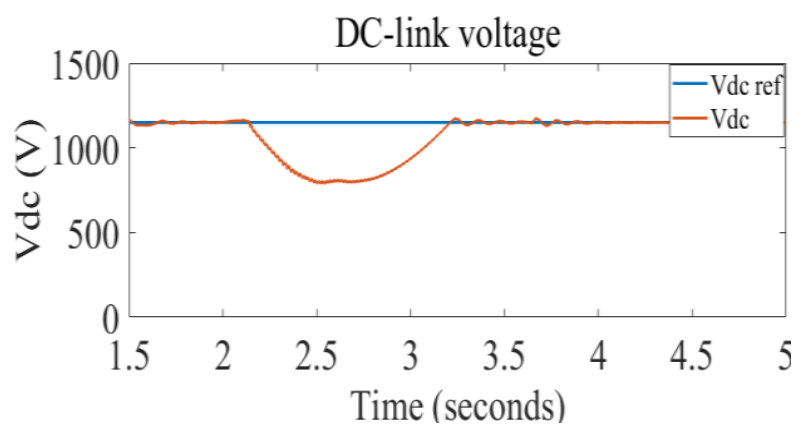

(b2)

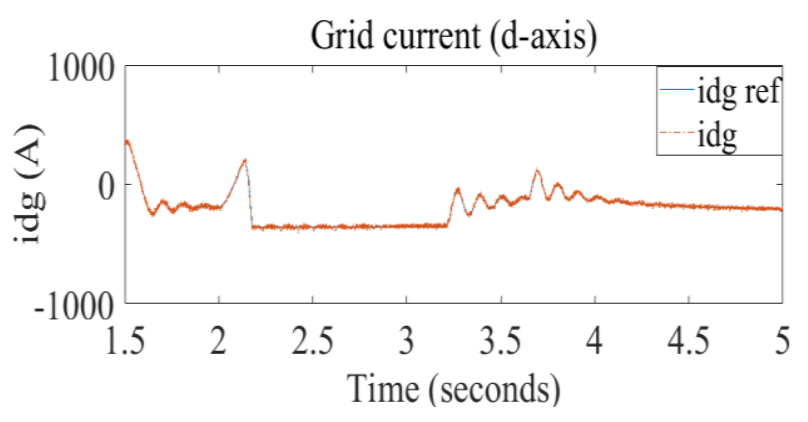

(c2)

Fig.15. Comparative analysis at GSC

\section{E. CONCLUSION}

When a three-phase symmetrical fault occurs at the grid terminal, high stator current occurs and this high stator current is further transmitted to the rotor winding due to the magnetic coupling between the two windings. Moreover, the dc-link voltage is increased as the energy flows through the capacitor and will damage the converters if additional protection system is added. Thus, in this study crowbar protection system is implemented near the RSC to secure it from excess energy. A comparison of crowbar with existing capacitor bank is rendered. From the simulation result it is observed that the crowbar protection system indeed protects the converts by ensuring the current flows through the resistance. The high DC-link voltage that is observed with using capacitor bank is reduced when crowbar is activated. Thus, it is concluded that the crowbar protection system is essential for improvement of the performance of the machine during fault state.

\section{REFERENCES}

[1]. Devashish, A. Thakur, S. Panigrahi, and R. R. Behera, "A Review on Wind Energy Conversion System and Enabling Technology," 2016 International Conference on Electrical Power and Energy Systems (ICEPES), 2016.
[2]. Mahmoud Rihan, O. Noureldeen, and B. Hasanin, "Behavior Improvement of Doubly-Fed Induction Generator Wind Farms during Grid Fault Occurrence," in 17th International Middle East Power Systems Conference, 2015.

[3]. Rabie Gohar and Servati. F, "Modeling a DFIGBased Wind Turbine Focusing on DFIG and Aerodynamic Models," European Online Journal of Natural and Social Sciences, vol. 3, no. 3, pp. 744-757, 2014.

[4]. Sherif. O, Zain Elabideen, A. A. Helal, and I. F. ElArabawy, "Low Voltage Ride Through Capability Techniques for DFIG-Based Wind Turbines," International Journal of Electrical, Computer, Energetic, Electronic and Communication Engineering, vol. 10, no 7 pp. 910-918, 2016.

[5]. Z. Rafiee, M. Rafiee, and M. R. Aghamohammadi, "The Voltage Dip and Doubly-Fed Induction Generator with Considering Uncertainty Conditions," Bulletin of Electrical Engineering and Informatics, vol. 9, no. 1, pp. 30-38, 2020. 
[6]. Dehong Xu, F. Blaabjerg, W.Chen and N.Zhu, "Advanced Control of Double Fed Induction Generator for Wind Power System", John Wiley \& Sons Ltd, United Kingdom, 2018.

[7]. Gonzalo Abad, Jesús L, M. Rodríguez, L. Marroyo, and Grzegorz Iwanski "Doubly Fed Induction Machine: Modeling and Control for Wind Energy Generation Applications", Wiley-IEEE Press,2011.

[8]. Haitham Abu-Rub, Mariusz Malinowski, Kamal AlHaddad, "Power Electronics for Renewable Energy Systems, Transportation and Industrial Applications", John Wiley \& Sons Ltd, United Kingdom, pp. 9-12, 2014.

[9]. Aman Abdulla Tanvir, "Control System for Doubly Fed Induction Generator Based Wind Energy Conversion System," Master's Thesis, 2016.

[10]. Boyu Qin, Hengyi Li, Xingyue Zhou, Jing Li, and Wansong Liu, "Low-Voltage Ride-Through Techniques in DFIG-Based Wind Turbines: A Review," Applied Sciences, vol. 10, p. 2154, 2020.

[11]. M. El-Moursi, P. Kaliannan, R.A. Jerin A, and U. Subramaniam, "A Review on Fault Ride Through Solutions for Improving Transient Stability in DFIG Based Wind Turbines, IET Renewable Power Generation, vol.12, pp. 1786 - 1799, 2018.

[12]. Ehsan Dadashnialehi, "Modeling and Control of Variable Speed Wind Turbines", Master's Thesis, 2012. [13]. Amer Obaid Kareem "Performance Analysis of Doubly-Fed Induction Generator (DFIG)- Based Wind Turbine with Sensor and Sensorless Vector Control", Ph.D. Thesis, 2016.
[14]. Ayala. E, Simani. S, Pozo, N. and Muñoz. E "Indirect Speed Control Strategy for Maximum Power Point Tracking of the DFIG Wind Turbine System.," Revista Técnica Energía, Vol. 17, Issue 2, pp. 92-101, 2021.

[15]. Jackson John Justo, Francis Mwasilu, and JinWoo Jung, "Doubly-Fed Induction Generator-Based Wind Turbines: A Comprehensive Review of Fault RideThrough Strategies", Renewable and Sustainable Energy Reviews Elsevier, vol. 45, pp. 447-467, 2015.

\section{Creative Commons Attribution License 4.0 (Attribution 4.0 International, CC BY 4.0)}

This article is published under the terms of the Creative Commons Attribution License 4.0 https://creativecommons.org/licenses/by/4.0/deed.en_US 